Ekbom (1947) using "gynergen" ${ }_{1}$ reported results similar to our own. It has been our impression that gastro-intestinal side-effects were less riarked with migril than with other preparations, but we have no statistically valid evidence to support this view.

We are unable to throw any light on the aetiology of this condition. We see no reason why it should be attributed to histamine allergy and it is also difficult to relate it to migraine. In our cases a family history of migraine was rarely obtained, and this would be unexpected if this condition was indeed a variant of the migraine syndrome in which a positive family history is the rule rather than the exception. The age and sex distribution is also somewhat different from that of migraine, many of our patients having had their first symptoms in their forties. Though these are only two facets of the clinical picture, they may be of possible significance in distinguishing this syndrome from migraine.

\section{Summary}

Twenty-eight cases of periodic migrainous neuralgia are reviewed. The clinical picture is described. The average time which elapsed between the onset of symptoms and accurate

"Known in Great Britain as " femergen." diagnosis was 6.5 years. Our experiences of treatment using prophylactic migril in 20 patients are discussed. In 14 the response was satisfactory and in six relief was only slight. Two of these patients showed further improvement on prophylactic ergotamine injections. Three patients who failed to respond to oral ergotamine or relapsed responded to methysergide. A plea is made for early diagnosis in this eminently treatable condition.

We are grateful to Dr. Henry Miller for allowing us to review a number of patients who were under his care.

\section{REFERENCES}

Bickerstaff, E. R. (1959). Lancet, 1, 1069

Eagle, W. W. (1942). Arch. Otolaryng., 35, 66.

Ekbom, K. A. (1947). Acta psychiat. (Kbh.), Suppl. No. 46, p. 106. Friedman, A. P. (1963). Neurology (Minneap.), 13, No. 3, Pt. 2, p. 27. Gardner, W. J., Stowell, A., and Dutlinger, R. (1947). F. Neurosurg., 4, 97.

Harris, W. (1926). Neuritis and Neuralgia. Oxford Publications, London. (1936). Brit. med. F., 1, 457.

Horton. B. T. (1941). F. Amer. med. Ass., 116, 377.

MacLean, A. R., and Craig, W. McK. (1939). Proc. Mayo Clin., 14, 257.

Kunkle, E. C., Pfeiffer, J. B., jun., Wilhoit, W. M., and Hamrick, L. W., jun. (1952). Trans. Amer. neurol. Ass., 77, 240.

Lance, J. W., Fine, R. D., and Curran, D. A. (1963). Med. F. Aust., 1, 814 .

Sluder, G. (1908). N.Y. Med. F., 87, 989.

Vail, H. H. (1932).'Ann. Otol.'(St. Louis), 41, 837.

\title{
Clinical Trial of Inhaled Ergotamine Tartrate in Migraine
}

\author{
J. CROOKS,* M.D., F.R.C.P.ED., M.R.C.P., M.R.C.P.GLASG. ; S. A. STEPHEN, † M.B., CH.B., M.R.C.P.ED. \\ W. BRASS, $\ddagger$ M.A.
}

Brit. med. F., 1964, 1, 221-224

Ergotamine tartrate has been the drug of choice for the symptomatic treatment of migraine for many years (Brock, et al., 1934), and the vasoconstrictive action which is the basis of its use was clearly demonstrated by Graham and Wolff (1937). Unfortunately ergotamine given orally has been shown to be less effective than when given by the parenteral or rectal route (Lennox and von Storch, 1935; Tunis and Wolff, 1953 ; Greene, 1959). Because the practical difficulties associated with ergotamine injections and suppositories limit their use, alternative routes of administration have been sought and a formulation of ergotamine tartrate suitable for oral inhalation (" medihaler-ergotamine") has recently been devised. Although a number of workers from other countries have reported favourably on its use (Finch, 1960 ; Graham et al., 1960 ; Blumenthal and Fuchs, 1961 ; Sutherland and Eadie, 1961 ; DalsgaardNielsen, 1961) their opinions were, in the main, based on uncontrolled observations. The present paper gives the results of a clinical trial of inhaled ergotamine tartrate in the treatment of migraine in which the therapeutic effectiveness of inhalation has been compared with that of the drug given sublingually. The trial was designed to solve the problem posed by a comparison of two different forms of administration of the same drug, as measured by a highly subjective response, by the use of a "double-blind" sequential procedure.

Selection of Patients.-Patients were accepted for inclusion in the trial if they satisfied the following criteria: (1) the duration of complaint of episodic headache had to exceed two years; (2) a family history of episodic headache had to be present; (3) the patient had to have on average two or more attaclss of headache monthly ; (4) the headache had to have a unilateral element ; (5) one or more of the following symptoms had to be associated with the headache; nausea, vomiting, photophobia, diplopia, scotomata, blurring of vision, fortification spectra, paraesthesiae ; and (6) physical signs of neurological disease had to be absent.

Procedure for Inhalation of Ergotamine Tartrate.-A convenient portable apparatus for the self-administration of micronized ergotamine tartrate suspended in an inert aerosol propellant (medihaler-ergotamine) was used. The device was calibrated to deliver a fixed dose of $0.36 \mathrm{mg}$. of ergotamine tartrate per single inhalation. Each patient was taught how to use the device and given both verbal and written instructions to take one inhalation as soon as possible after the onset of a headache, with further single inhalations every 5 to 10 minutes until the headache had gone or a maximum of five inhalations had been reached. The procedure was not to be repeated within 24 hours. The maximum dose of ergotamine tartrate which could be taken during the first hour of an attack was thus $1.8 \mathrm{mg}$.

Procedure for the Sublingual Administration of Ergotamine Tartrate.-Tablets containing $1 \mathrm{mg}$. of ergotamine tartrate were used. Each patient was instructed to place one tablet beneath the tongue as soon as possible after the onset of the headache and to allow the tablet to dissolve. The average dissolution time of the tablets was five minutes. If the headache had not gone within half an hour another tablet was to be taken. No \footnotetext{
* Senior Lecturer, Department of Materia Medica and Therapeutics,
University of Aberdeen.

† Late Senior Registrar, Aberdeen Royal Infirmary.

¥ Senior Lecturer in Statistics, Department of Statistics, University of Aberdeen.
} 
further tablet had to be taken within 24 hours. The maximum dose of ergotamine tartrate taken during the first hour of an attack was thus $2 \mathrm{mg}$.

\section{Design and Analysis of Trial}

\section{Double-blind Sequential Procedure}

The aim of the trial was to determine whether the inhalation of ergotamine tartrate gave symptomatic relief in migraine more effectively than the sublingual tablet using a standard procedure for each type of treatment. Because the sublingual route is less complicated the possibility that it might give better results was believed to be of little interest since it would, in general, be preferred when the therapeutic effects were equal. The trial was therefore designed to test the hypothesis that the inhalation procedure was superior against the alternative that the use of the sublingual route was at least as good.

Since the drug is very effective when given parenterally early in an attack, it seemed probable that inhalation would either be similar to or substantially better than the sublingual tablet for initiating the pharamacological effect of the drug. Because this is the situation in which sequential experiments are most efficient the trial was designed to discriminate between these possibilities.

Measurements of the relief of pain contain a large subjective element which varies from individual to individual. It was form in terms of the order (rank) of the categories of relief for that patient. Conversely, a failure was recorded when there was relatively more improvement with the tablet by the same criterion. When no decision could be made on this basis about the merits of the two methods of taking the drug the results were discarded as a tie giving no information on which was the better.

The measurement system does not imply any assumption about the scale of pain relief. If the drug inhaled gave a higher relief category than the corresponding dummy and the drug in tablet form gave the same or a lower category compared with its dummy a success was scored; it was also a success if both methods of taking the drug gave more relief than their dummies, but the inhaled categories bracketed those with the tablet and had a larger difference. If the drug and dummy inhalations gave the same category but the drug given sublingually did worse than its dummy a success was also counted. In practice the simplest way of applying the system is to order the relief categories of the attacks for each patient separately and number them from the lowest up. The sum of the orders for dummyinhaled and drug tablet was subtracted from the sum for druginhaled and dummy tablet. If the result was positive a success was scored, if zero a tie, and if negative a failure. This is not a scoring system in the accepted sense, since the rank of a category will vary for different patients, but a convenient method of arriving at the correct assessment. A few typical sets of results with the derived measurement are shown in Table I.

TABLE I

\begin{tabular}{|c|c|c|c|c|c|c|c|c|c|}
\hline \multirow{2}{*}{ Case No. } & \multicolumn{8}{|c|}{ Categories of Relief } & \multirow{2}{*}{ Assessment } \\
\hline & \multicolumn{2}{|c|}{ Drug inhaled } & \multicolumn{2}{|c|}{ Dummy inhaled } & \multicolumn{2}{|c|}{ Drug tablet } & \multicolumn{2}{|c|}{ Dummy tablet } & \\
\hline $\begin{array}{r}7 \\
12 \\
18 \\
6\end{array}$ & $\begin{array}{l}\text { Within } 1 \text { hour } \\
\text { No improvement } \\
\text { Within } 2 \text { hours } \\
\text { Headache less } \\
\text { Within } 1 \text { hour }\end{array}$ & $\begin{array}{l}(3) \\
(1) \\
(3) \\
(1) \\
(4)\end{array}$ & $\begin{array}{l}\text { No improvement } \\
\text { No improvement } \\
\text { No improvement } \\
\text { Within } 2 \text { hours } \\
\text { Within } 2 \text { hours }\end{array}$ & $\begin{array}{l}\text { (1) } \\
(1) \\
(1) \\
(2) \\
(3)\end{array}$ & $\begin{array}{l}\text { Within } 3 \text { hours } \\
\text { Within } 2 \text { hours } \\
\text { Headache less } \\
\text { Within } 2 \text { hours } \\
\text { Headache less }\end{array}$ & $\begin{array}{l}(2) \\
(2) \\
(2) \\
(2) \\
(2)\end{array}$ & $\begin{array}{l}\text { Within } 3 \text { hours } \\
\text { No improvement } \\
\text { No improvement } \\
\text { Within } 2 \text { hours } \\
\text { No improvement }\end{array}$ & $\begin{array}{l}(2) \\
(1) \\
(1) \\
(2) \\
(1)\end{array}$ & $\begin{array}{l}\text { Success } \\
\text { Failure } \\
\text { Success } \\
\text { Failure } \\
\text { Tie }\end{array}$ \\
\hline
\end{tabular}

Ranking of categories of relief for each patient is shown in parentheses.

therefore decided that comparisons of the different methods of giving the drug should be "within patients"-that is, each individual would try both procedures to eliminate the variations in response between patients. Again, because of possible subjective effects, it was considered to be essential that the trial should be blind-that is, that the patient's judgment should not be influenced by a knowledge of the treatment given and his interpretation of the expected results. Since it was impossible to disguise the difference between the use of tablet and inhaler two control "dummy" treatments were introduced. Every patient was then treated in four ways-namely, with drug inhaled, dummy inhaled, drug sublingually, and dummy tablet sublingually. A series of random orders of the four treatments was listed, and from this the hospital pharmacist allocated the drug and dummy preparations. The trial was double-blind, since neither the patient nor the physician knew which treatments were the drug and which the inert preparations.

\section{Method of Measuring Response}

The patients were asked to record for each treatment the degree of relief obtained on a very broad scale-namely, headache gone within one hour, within two hours, within three hours, headache less within three hours, no change. Any improvement after three hours was regarded as unlikely to be related to the treatment and was not distinguished from no change. These five categories were taken to show progressively less relief of the migraine headache. The observations for a patient were taken to signify a success for the inhalation procedure if the drug relative to the dummy inhaled gave more improvement than the drug relative to the dummy in tablet

\section{Method of Analysis}

With this system of measurement the analysis of the data is simply of the proportion of successes among the definite results - that is, ignoring ties. If the drug is at least as effective in tablet form as inhaled the proportion of successes in the population of patients will be one-half or less ; if inhalation is much superior the proportion of successes will be high. The sequential trial was designed to compare the hypothesis that the proportion of successes in the population was 0.5 against the alternative that the proportion was 0.8 at approximately $95 \%$ confidence levels.

It is usual and suitable to show the results of sequential trials graphically (see Chart). In this instance the number of observations is shown along the horizontal axis and the number of successes minus failures on the vertical. The observations are thus illustrated as a path on the graph. When the path reaches a boundary point the trial ends. The boundaries are here drawn so that the probabilities of reaching the upper one if the population proportion of successes is 0.5 and of reaching the lower one if the proportion is 0.8 are just under $5 \%$. This sequential design was devised specially for the present experiment and is a closed one-that is, an upper limit of 31 observations was set to the size of the trial.

\section{Results}

As can be seen from the Chart the path of sample results reached an upper boundary point after 13 definite results, of which 11 were successes and two failures. There were also 
six tied results. The trial thus covered 19 patients who had 76 attacks and indicated that inhalation of the drug is more effective than sublingual administration. The record for one patient who lost the schedule but for whom verbal reports were obtained later was not included (in fact, the score as given was a tie); another patient did not fill in the schedule correctly and it was rejected.

The evidence from the sequential analysis that inhalation of the drug is more successful than treatment by tablet is satisfactory but it gives no direct estimate of the size of the advantage. This can be examined from the distribution of patients by the relief obtained with different treatments shown in Table II.

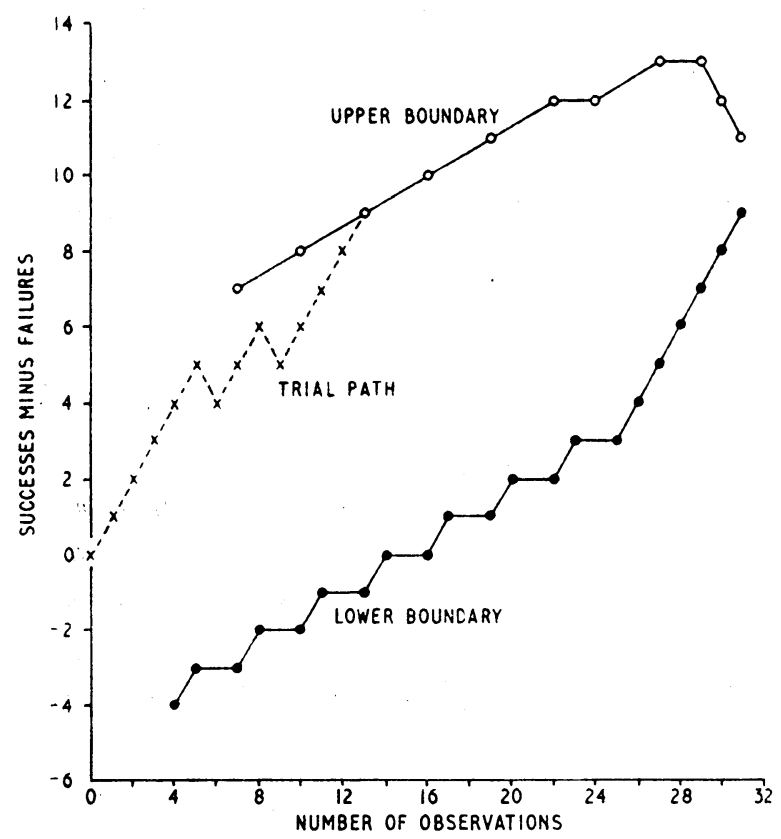

The cumulated record of results is shown by the trial path produced by moving one unit horizontally to the right and one unit vertically-up for a success and down for a failure. The superiority of inhaled ergotamine over the sublingual tablet was demonstrated after 13 definite scores.

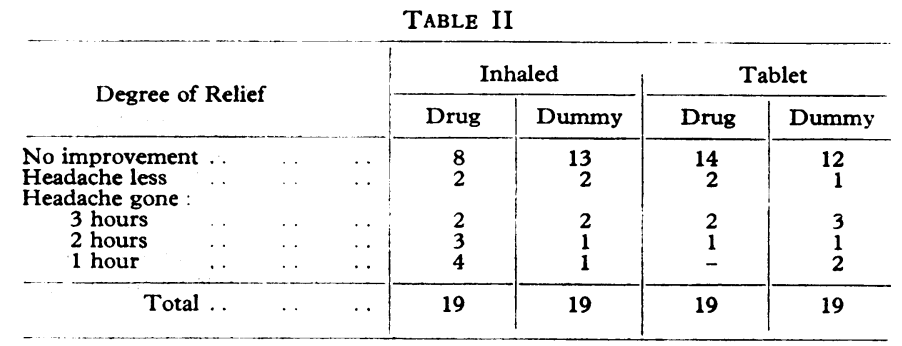

The performances of the two dummy treatments and the drug in tablet form are almost identical. There is therefore no evidence either that the use of the drug by tablet gave any relief or that the method of treatment (inhaler or tablet) influenced differentially the assessment of the effect. In about one attack in three some relief was obtained which could not be attributed to any treatment. To what extent this was due to natural remission or to the psychological influence of the belief that treatment had been given cannot be determined from the trial.

The improvements achieved when the drug was inhaled are notably better, although even here no relief was obtained in about 4 out of every 10 attacks. The most striking advantage is that in 7 out of 19 attacks the headache was gone in under two hours, compared with an average of 2 out of 19 for the drug tablet and controls.

The patients were asked to report for each attack and treatment any accompanying side effects. The common reports were of vomiting or nausea, distributed as follows :

\begin{tabular}{|c|c|}
\hline Treatment & $\begin{array}{l}\text { Attacks with } \\
\text { Nausea or Vomiting }\end{array}$ \\
\hline $\begin{array}{l}\text { Drug inhaled } \\
\text { Dummy inhaled } \\
\text { Drug tablet... } \\
\text { Dummy tablet }\end{array}$ & $\begin{array}{l}8 \\
3 \\
6 \\
5\end{array}$ \\
\hline
\end{tabular}

It will be noted that there were 11 instances each for treat. ment by tablet and inhaler. If the nausea and vomiting wert due to the migraine there is no indication that the attacks treated by the inhaled drug were less severe than the others On the other hand, there is no evidence that any side-effects of the drug were appreciably more severe when it was taken br inhaler than when taken by tablet.

\section{Discussion}

How far the sequential design used in this trial achieved $t$ : aims can be examined by comparing the results with the prescribed characteristics. The exact probability that the triai path would reach the upper boundary was $4.9 \%$ for the hyputhesis that 0.5 of the patients in the population would be " successes" for the inhalation treatment ; the probability of the trial path reaching the lower boundary was $4.7 \%$ for th: alternative hypothesis that 0.8 of the patients would bx "successes." For these two hypotheses the expected length: of the trial-that is, the mean numbers of untied observation: required-are 13 and 15 respectively : the equivalent fixec sample experiment to give the same prescribed probabilitie: requires 25 untied observations. The trial finished in $1:$ observations, very close to the expected number. Since ther: was no indication that treatment by the inhaler introduced \& differential subjective effect in the assessment of pain relief, tint trial would have been valid without the two dummy controis This finding is of great interest and suggests that the facto: of spontaneous remission may be a greater hazard than th: placebo effect in evaluating drugs in the treatment of migraine

Under the conditions of the present trial inhaled ergotamin. tartrate aborted the migraine attack more effectively than ti: sublingual tablets, although the maximum dose of ergotamin: administered over one hour by either route was approximatel the same. The greater effectiveness of inhalation may be explained by higher blood concentrations of the drug produced early in the attack by absorption through the very vascular epithelium of the respiratory tract, although this would be difficult to prove because of the technical obstacles to measuring ergotamine in blood. The clinical trial of inhaled ergotamine with criteria of response which most closely approximate to those of the present investigation is that of Graham et al. (1960), whose uncontrolled study defined a "good" result as headache stopped within three hours ; "fair," meaning headache stopped in three to six hours; and "poor," meaning headache not stopped in six hours. These workers obtained good results with inhaled ergotamine in $57 \%$ of 246 attacks, which compares with the equivalent figure of $47 \%$ in the present trial. When comparing the efficacy of inhaled and sublingual ergotamine it must be remembered that the sublingual preparation used in the trial contained $1 \mathrm{mg}$. of ergotamine and had a much longer dissolution time than more recent formulations of ergotaminefor example, "lingraine" (2 mg. of ergotamine tartrate). Graham et al. (1960) suggested that this preparation (marketed in the U.S.A. as "ergomar") was less effective than inhaled ergotamine (medihaler-ergotamine), but the uncontrolled design of their investigation makes the significance of this finding doubtful. An experimental design similar to that of the present trial could be used to compare inhaled ergotamine with the newer sublingual preparations, and it is proposed to do this.

The undesirable symptoms associated with ergotamine treatment in the present trial were nausea and vomiting. There is no way of knowing when these were due to the drug and when to the migraine. They occurred equally often in the inhaled 
and sublingual preparations, which suggests that the effectiveness of inhalation was not due to the occurrence of nausea and vomiting less often in attacks when the inhaler was used. Other recorded side-effects of ergotamine, such as paraesthesiae, muscle cramps, joint pains, coldness of extremities, or intermittent claudication, were not found in the present study. In one patient treated subsequently, inhalation of ergotamine tended to produce mild dyspnoea due to bronchospasm, but she received such symptomatic relief of her migraine that she was prepared to accept this side-effect. Graham et al. (1960) reported a similar side-effect in one patient, subject to asthma, who observed that an asthmatic attack was precipitated by inhaled ergotamine.

In conclusion the use of ergotamine by inhalation (medihalerergotamine) appears to be more effective than sublingual ergotamine tablets, with a dissolution time of five minutes. Its efficacy compared with the newer sublingual preparations remains to be tested. Apart from nausea and vomiting, which may have been due to the migraine and not to the drug, sideeffects were not encountered in the patients studied in this trial. In view of the known side-effects of ergotamine, however, inhaled ergotamine is contraindicated in pregnancy, in vascular disease, particularly coronary artery disease, and in hepatic and renal disease.

The disappointments of oral treatment have led many thousands of migraine sufferers to medicate themselves with non-ergotamine preparations (Sweetnam, 1961). The development of preparations of ergotamine which allow the drug to be given by inhalation appears to increase the probability of a satisfactory therapeutic response. It must be borne in mind, however, that the best results in the treatment of migraine by ergotamine preparations are obtained when the dose and method of administration are tailored to the individual requirements of each patient.

\section{Summary}

The therapeutic effectiveness of inhaled ergotamine tartrate (medihaler-ergotamine) has been compared with that of the sublingual route (tablet with dissolution time of five minutes) in the symptomatic relief of migraine.

The maximum total dose of inhaled ergotamine was $1.8 \mathrm{mg}$. and of the sublingual drug $2 \mathrm{mg}$.

A double-blind sequential clinical trial was carried out which demonstrated that under the conditions of the investigation ergotamine tartrate was more effective when given by inhalation than by the sublingual route.

The drug when given sublingually was no more effective than inert preparations given by inhalation or sublingually.

No serious side-effects were encountered with either form of administration.

We would like to acknowledge the assistance of Dr. B. J. Hunt in the early stages of this trial, and the co-operation of Mr. H. N. F. Kinniburgh, group pharmacist, Aberdeen General Hospitals. We also wish to acknowledge the help of Riker Laboratories, who provided the necessary materials.

\section{REFERENCES}

Blumenthal, L. S., and Fuchs, M. (1961). Med. Ann. D.C., 30, 10 Brock, S., O'Sullivan, M. E., and Young, D. (1934). Amer. F. med. Sci. 188, 253.

Dalse, Ugeskr. Lag., 123, 448

Finch, J. W. (1960). Med. Tms (N.Y.), 88, 1029 .

Graham, J. R., Malvea, B. P., and Gramm, H. F. (1960). New Engl. 7. Med., 263, 802.

Med., 263, 802.

Greene, R. (1959). Brit. med. F., 1, 574.

Lennox, W. G., and von Storch, T. J. C. (1935). F. Amer: med. Ass., $105,169$.

Sutherland, J. M., and Eadie, M. J. (1961). Med. F. Aust., 48, 740.

Sweetnam, M. T. (1961). F. Coll. gen. Practit., 4, 538.

Tunis, M. M., and Wolf, H. G. (1953). Med. Clin. N. Amer., 37, 1251

\section{Medical Memoranda}

\section{Case of Thyroid Carcinoma in a Newborn Infant}

Brit. med. F., 1964, 1, 224-225

Thyroid carcinoma in the newborn is rare: Twelve cases were recorded by Winship and colleagues (Winship, 1956 ; Winship and Rosvoll, 1961a, 1961b) and a further one was noted by Hayles et al. (1960).

\section{CASE History}

A full-term African female infant was born at the Kaonde Hospital, Kasempa, Northern Rhodesia, on 4 January 1963, by caesarean section for placenta praevia and ante-partum haemorrhage. The infant had a very large thyroid gland, causing the neck to be extended. Irregular inspiratory efforts were made, but there was no cry. Resuscitative measures were ineffective and the infant's heart-beat soon ceased. The mother had minimal symmetrical enlargement of both thyroid lobes without nodules or signs of hyperthyroidism. There was no history of maternal irradiation.

Post-mortem Examination.-The thyroid gland measured $5.3 \mathrm{~cm}$. across the lateral lobes. On opening the trachea the lumen was seen to be almost occluded by a smooth tumour bulging from the left side of its wall and extending upwards to within $0.5 \mathrm{~cm}$. of the left vocal fold. On cutting across the thyroid the tissue around the trachea and in its left wall was seen to be yellow for a total diameter of $1.5 \mathrm{~cm}$., in contrast with the plum colour of the rest of the gland. The cartilaginous wall of the trachea was eroded and breached by the yellow tissue. The lungs appeared well aerated. No other abnormality was found.

Histology.-The yellow tissue noted in the thyroid was composed of irregular follicles with marked variability in cell size and shape

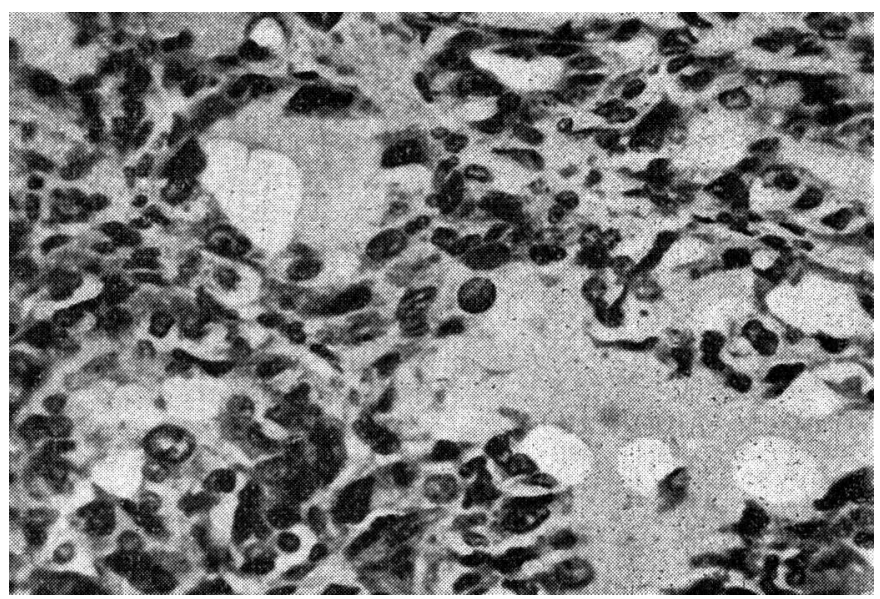

The tumour in the tracheal wall. Obvious colloid-filled follicles are present. The cells show marked variability in size and form. (Celestin blue, haemalum, and eosin. $\times 266$.) 